\title{
Editorial
}

\section{Assessment of diet and physical activity: new tools; old challenges}

\section{Special issue on methodology}

The assessment of diet and physical activity in populations is central to research and practice of public health nutrition. Choosing the best method for each study and setting requires both technical experience and up-to-date knowledge. With the explosive growth of information technology, the potential for data capture on diet, activity and the environmental context by novel methods such as digital cameras, mobile phones and global positioning systems is being explored. In this issue Nelson-Laska et $_{\text {al. }}{ }^{(1)}$ show the potential of Personal Digital Assistants for capturing information about the context of eating in young adults while Baranowski et $\mathrm{al}^{(2)}$ highlight the possibilities of digital images to assess portion size in children. These additions to the tools available for dietary assessment open up new possibilities for the type and quality of dietary data collection.

\section{Development and validation of methods}

While some methods such as the weighed food record and FFQ have been widely used, in recent times we have been forced to recognise that these have pitfalls of their own. Under-reporting of food intake is a challenge for weighed records ${ }^{(3)}$, while concerns about the performance of FFQ in epidemiological studies have also been aired ${ }^{(4)}$. Lutomski et $a l^{(5)}$ report on characteristics of under- and overreporters in a national survey of diet in Ireland. Papers by Gwynn et al..$^{(6)}$ and Dutman et al. ${ }^{(7)}$ report validation studies in populations as diverse as Caribbean adults and Australian Aboriginal children, highlighting the importance of validation for each application and population, while the results of Pakseresht $e t a l{ }^{(8)}$ demonstrate how validity can differ between nutrients from the same questionnaire. Validation of different physical activity questionnaires in different study populations is also important, and Pettee Gabriel et al. ${ }^{(9)}$ and Macfarlane et al. ${ }^{(10)}$ demonstrate this in action. Abu Saad et $a l .{ }^{(11)}$ show how food frequency data can be used to develop rapid assessment tools and Ward et al. ${ }^{(12)}$ describe the impact of open $v$. closed questions on estimates of alcohol intake.

\section{Nutrient composition of foods and supplements}

Even with high-quality dietary assessment, translation of data into nutrient intake relies on the accuracy of food composition data. Chemical analysis of foods is an expensive and labour-intensive process, but with more processed foods coming on to the market and with reformulation of existing foods by manufacturers it is an increasing challenge to keep up to date with quality assured. Another important issue where manufacturers' data are used is in the assessment of supplement intake. Lentjes et $a l^{(13)}$ describe a comprehensive approach to collecting data from supplement labels and assumptions made in estimating nutrient intake in the adults taking part in the EPIC-Norfolk study: the need for this is demonstrated by the fact that $40 \%$ took a supplement at least $1 \mathrm{~d}$ in the $7 \mathrm{~d}$ of their diet diary. Given the substantial effort involved in this process, the possibility of sharing both this methodology and the burden of maintaining the information could be a worthwhile exercise.

\section{Food labelling}

With the huge growth in processed foods worldwide, food labelling is an important issue for consumers. Tao et al. ${ }^{(14)}$ describe the low proportion of foods labelled and deficiencies in the information presented on foods available in China prior to recent legislation. Jacobs et al. ${ }^{(15)}$ describe barriers to understanding labels in South African adults, while Elliott and Conlon ${ }^{(16)}$ show how different criteria for assessing sodium levels in children's foods can give different results.

\section{Other approaches}

For some nutrients such as heavy metals, conventional dietary assessment methods may not be appropriate as the nutrient content of foods varies so highly and is poorly covered by food composition tables. Biomarkers can be used to indicate key food sources, as shown for methylmercury by Airaksinen et al. ${ }^{(17)}$.

Food balance sheets, which describe production, imports and exports for commodities for each country in relation to population size, are published annually for each country by FAO yet are rarely used in nutrition research. Sheehy and Sharma ${ }^{(18)}$ show how this information can be used to estimate the impact of fortification of specific foods on population nutrient intake. With increasing concern about national and global food security, FAO data may be increasingly useful for population research. 
Overall it is an exciting time to be involved in diet and physical activity assessment. We hope you will enjoy this issue and look forward to receiving more papers on this area in the future.

Agneta Yngve

Editor-in-Chief

Marilyn Tseng

Allison Hodge

Geraldine McNeill

Irja Haapala

Deputy Editors

\section{References}

1. Nelson Laska M, Graham D, Moe S et al. (2011) Situational characteristics of young adults' eating occasions: a real-time data collection using Personal Digital Assistants. Public Health Nutr 14, 472-472.

2. Baranowski T, Baranowski JC, Watson KB et al. (2011) Children's accuracy of portion size estimation using digital food images: effects of interface design and size of image on computer screen. Public Health Nutr 14, 418-425.

3. Livingstone MBE, Prentice AM, Strain JJ et al. (1990) Accuracy of weighed diet records in studies of diet and health. BMJ 300, 708-712.

4. Kristal AR, Peters U, Potter JD (2006) Is it time to abandon the food frequency questionnaire? Cancer Epidemiol Biomarkers Prev 15, 1054.

5. Lutomski JE, van den Broeck J, Harrington J et al. (2011) Sociodemographic, lifestyle, mental health and dietary factors associated with direction of misreporting of energy intake. Public Health Nutr 14, 532-541.

6. Gwynn JD, Flood VM, D'Este CA et al.on behalf of the Many Rivers Diabetes Prevention Project study team (2011) The reliability and validity of a short FFQ among Australian Aboriginal and Torres Strait Islander and non-Indigenous rural children. Public Health Nutr 14, 388-401.
7. Dutman AE, Stafleu A, Kruizinga A et al. (2011) Validation of an FFQ and options for data processing using the doubly labelled water method in children. Public Health Nutr 14, 410-417.

8. Pakseresht M, Sharma S, Cao X et al. and The Barbados National Cancer Study Group (2011) Validation of a quantitative FFQ for the Barbados National Cancer Study. Public Health Nutr 14, 426-434.

9. Pettee Gabriel K, McClain JJ, Schmid KK et al. (2011) Reliability and convergent validity of the past-week Modifiable Activity Questionnaire. Public Health Nutr 14, 435-442.

10. Macfarlane D, Chan A \& Cerin E (2011) Examining the validity and reliability of the Chinese version of the International Physical Activity Questionnaire, long form (IPAQ-LC). Public Health Nutr 14, 443-450.

11. Abu-Saad K, Shai I, Vardi H et al. (2011) Rapid assessment tools for ranking pregnant minority women into multinutrient exposure groups. Public Health Nutr 14, 379-387.

12. Ward H, Luben RN, Wareham NJ et al. (2011) CHD risk in relation to alcohol intake from categorical and open-ended dietary instruments. Public Health Nutr 14, 402-409.

13. Lentjes MAH, Bhaniani A, Mulligan AA et al. (2011) Developing a database of vitamin and mineral supplements (ViMiS) for the Norfolk arm of the European Prospective Investigation into Cancer (EPIC-Norfolk). Public Health Nutr 14, 459-471.

14. Tao Y, Li J, Lo YM et al. (2011) Food nutrition labelling practice in China. Public Health Nutr 14, 542-550.

15. Jacobs SA, De Beer H, Larney M (2011) Adult consumers' understanding and use of information on food labels: a study among consumers living in the Potchefstroom and klerksdorp regions, South Africa. Public Health Nutr 14, 510-522.

16. Elliott CD \& Conlon MJ (2011) Toddler foods, children's foods: assessing sodium in packaged supermarket foods targeted at children. Public Health Nutr 14, 490-498.

17. Airaksinen R, Turunen AW, Rantakokko P et al. (2011) Blood concentration of methylmercury in relation to food consumption. Public Health Nutr 14, 480-489.

18. Sheehy T \& Sharma S (2011) Use of FAO food balance sheets to estimate the potential ability of novel folateenriched eggs to increase the folate supply in European Union countries. Public Health Nutr 14, 551-556. 